\title{
"A MÃE DOS CONTOS": Uma Proposta de Leitura \\ Intertextual
}

Sandra Lopes Monteiro*

$\mathbf{M}$

il e uma paiginas tèm sido escritas para se contar e recontar As mil e uma noites. $O$ conto que apresentamos aqui, reaviva passagens desses consagrados contos árabes.

Em “A mãe dos contos" de Henri Gougaud (1989), o autor inicia a narrativa indagando e respondendo sobre a origem dos contos, o porqué e o como. E atribui a uma esposa triste de um rude lenhador, personagens do conto, o conhecimento desse segredo. O texto apresenta a luta dessa mulher que durante nove meses, todas as noites, inventou histórias para preservar a vida que ela trazia em seu ventre. E o autor encerra o conto afirmando que na arte de contar histórias dessa esposa triste nasceram todos os contos da Terra.

"A mãe dos contos" liga-se mais estreitamente ao conceito de história e do contar histórias, e refere-se, sobretudo, ao conto maravilhoso, com personagens não determinadas historicamente. $E$ narra como "as coisas deveriaun acontecer", satisfazendo assim uma expectativa do leitor e contrariando o

* Universidade Federal do Parani.

I As mil e uma noites, contos árabes de autor ou autores desoonhecidos, começam a circular na Pérsia por volta do século X, mais tarde, no sciculo XII vèn para o Egito e, finalmente, no sćculo XVIII espalhami-se por toda a EuropxI, sendo publicados $\mathrm{cm} 1814 \mathrm{~cm}$ Calcuta. 
universo real, em que nem sempre as coisas acontecem da forma que gostaríamos.

Para tecermos alguns comentários a respeito do conto "A mãe dos contos" e daquela que consideramos uma de suas fontes, As mil e uma noites, fomos buscar, entre dilerentes autores, subsídios teóricos em Koch (1989, p. 88 ), quando trata do caráter intertextual dos textos.

... a intertextualidade compreende as diversas maneiras pelas quais a produção e recepção de dado texto depende do conhecimento de outros textos por parte dos interlocutores, isto é, diz respeito aos fatores que tornam a utilização de um texto dependente de um ou mais textos previamente existentes.

É possivel estabelecer a intertextualidade entre esses dois contos a partir de fatores relativos ao conteúdo, à forma $\mathrm{e}$ aos tipos textuais.

A proximidade evidente de conteúdo entre "A mãe dos contos" e As mil e uma noites não se deve tão somente a questões específicas de conhecimento de mundo, mas também às fontes consultadas por Henri Gougaud (1989, p. 359-360).

Quando nos referimos a conhecimento de mundo (ou conhecimento partilhado entre individuos, ou mesmo conhecimento armazenado) partimos do princípio que todos, em algum momento de suas vidas já ouviram falar $\mathrm{d} A s$ mil e uma noites. Talvez scja menos conhecida a fábula que deu origem Às mil $e$ uma noites.

Prevalece tanto na fábula $O$ burro, o boi e o trabalhador (texto-fonte) como nos contos árabes (texto-segundo) o caráter de obstinação de seus personagens, ressaltando que o texto-segundo guardou muito bem esta caracteristica.

$\mathrm{Na}$ fábula vemos o burro (referido pelo boi como o "iluminado") aconscllhando o boi a mudar de atitude em relação ao seu dono. $O$ boi que trabalhava de sol a sol sente inveja do burro que só trabalhava esporadicamente.

Tantos são os conselhos do burro para o boi que este, aprendendo a se fazer de doente, acaba por inverter a situação do burro que passa a ser explorado no trabalho duro do dia-a-dia. Como o dono dos animais tem o dom de entendê-los, passa então a manipular a situação, fazendo cada um pagar pelas suas próprias palavras e atitudes. Por fim, o burro diante de uma situação de maus tratos se vê forçado a reconhecer a sua imprudência: 
C'est par mon imprudence, se disait-il à lui-mème, que je me suis attiré ce malheur: je vivais heureux, tout me riait, j'avais tout ce que je pouvais souhaiter; c'est ma faute si je suis dans ce déplorable état; et, si je ne trouve quelque ruse en mon esprit pour m'en tirer, ma perte est certaine. (L'ane, le boeuf et le laboureur, 1965, p. 39).

Essa fábula foi contada pelo grão-vizir do rei Shariar à sua filha Sheherazade que desejava dar um basta às barbáries que o sultão excrcia sobre as famílias da cidade. Sheherazade, condenada à morte, contava noite após noite histórias com o objetivo de distrair o rei, pois o plano do rei Shariar era de desposar uma virgem por noite, que morreria no dia seguinte, de modo que nenhuma pudesse repetir o ato de traição de sua antiga esposa.

Quando Sheherazade conta histórias ao rei, aguça-lhe cada vez mais a curiosidade. Ele quer continuar a ouvir a história na noite seguinte. $O$ conto ou a história, enquanto vida, acaba também encantando o rei. E Shcherazade, contando histórias, vai adiando a morte e prolongando a vida. Enquanto ela prolonga a sua própria vida, a esposa triste do rude lenhador, no texto de Gougaud, faz desabrochar uma outra vida.

Attends, mon maître, attends! J'ai appris aujourd'hui une histoire. Elle est belle. Écoute-la d'abord, tu me battras après. (Gougaud, 1989, p. 12).

Segundo Gougaud as narrativas que integram As mil e uma noites, às vezes milenares, que atingiram a glória, ainda que anônimas, existem para preservar momentos, ora de perdas, ora de ganhos. São histórias que seguem para frente. Ou para frente, retornando. Variam de assunto e no modo de contar. E completa dizendo que ele nāo é o autor dos contos que estão neste livro.

Je n'ai fait que les raviver, les ranimer, les restaurer, comme d'autres restaurent de vieux châteaux. J'ignore qui en sont les premiers auteurs. D'ailleurs, qu'importe? Ils sont au monde parce qu'ils sont nécessaires, conme l'air, comme la lumière du jour, comme les arbres. (L'arbre d'amour et de sagesse, contracapa). 
Esta afirmação se prende ao fato de que para escrever seu livro de contos ele consultou uma longa bibliografia que vem citada no fim do livro: outros contos, críticas e literatura complementar. Essas obras vão de 1918 a 1989.

O texto segundo Kristeva (1981, p. 25), “é uma intertextualidade, uma permutação de textos: no espaço de um texto vários enunciados, tomados a outros textos, se cruzam e se neutralizam. Todo tex to é uma absorção e transformação de uma multiplicidade de outros textos".

Naturalmente, quem ler "A mãe dos contos" sem conhecer As mil e uma noites, pode até the atribuir um sentido, pois de um mesmo texto são possiveis $n$ leituras. Mas certamente deixará de perceber muitas das significações explicitamente propostas pelo produtor do mesmo.

$\mathrm{Na}$ leitura $\mathrm{d} A$ s mil e uma noites e do conto objeto desta análise é possível verificar, por exemplo, que a triste esposa de um rude lenhador, ao contrário de Sheherazade, busca proteger uma única vida em lugar de uma coletividade.

Quanto à intertextualidade de caráter formal, ela pode estar ou não vinculada à tipologia textual. Limitar-nos-emos aqui a dar exemplos não ligados à tipologia, já que este aspecto será tratado mais adiante.

Verificamos no texto que o mesmo se inicia através de um tipo de questionamento bastante popular quando se busca averiguar a origem de alguma coisa.

Oủ sont donc nés les contes, et pourquoi, et comment? Une femme l'a su, aux premiers temps du monde. Qui l'a dit à la femme? L'enfant qu'elle portait dans son ventre. Qui l'a dit à l'enfant? Le silence de Dieu. Qui l'a dit au silence? (Gougaud, 1989, p. 11).

Esse questionamento inicial encontra o seu oposto no fechamento do texto. Ou scja, o narrador partindo do mais geral, do mais palpável para o mais particular, mais abstrato, constrói uma situação em que, inicialmente, se desconhece a origem dos contos; a resposta está numa verdade longínqua, infinita. Conclui com um movimento contrário, fazendo emergir do silêncio profundo, daquela criança no interior do ventre da esposa triste de um rude lenhador, contos, histórias maravilhosas, sábias.

A l'instant même un conte neuf naquit de sa bouche surprise. Comme la nuit passée son époux l'écouta, l'oeil rond, le poing tenu en l'air par un fil invisible. Le temps parut passer comme 
un souffle. A l'aube elle se tut. Il vit le jour, se dit qu'il lui fallait partir pour la forêt, prit sa hache, et s'en alla.

Et quand le soir tomba vint encore une histoire. Neuf mois, toutes les nuits, cette femme conta pour protéger la vie qu'elle portait dans le ventre. Et quand l'enfant fut né, l'homme connut l'amour. Et quand l'amour fut né, les contes des neuf mois envahirent la terre. Bénie soit cette mère qui les a mis au monde. Sans elle les bâtons auraient seuls la parole. (Gougaud, 1989, p. 13).

Outro aspecto relevante é o início da scgunda parte. A narrativa é introduzida através de uma expressão consagrada.

Il était pour la première fois, dans la grande forêt des premiers temps, un rude bûcheron et son épouse triste. Ils vivaient ... (Gougaud, 1989, p. 11).

Reconhecemos nesse início a forma como são contadas as histórias infantis, o início de algumas fábulas, etc. Porém, é preciso destacar que buscando, adaptar o objetivo do texto à expressão toda feita o autor utiliza a frase "Uma única vez", ao invés de "Era uma vez", para atribuir à personagem feminina do texto a origem dos contos, que no seu entender não é diversa, mas única.

Também da fábula o texto guarda a conclusão, pois cle cncerra através de uma lição e de uma moral. A obstinação e a prudência da esposa fizeram-na vencedora de uma situação insustentável.

Um terceiro aspecto é a proposição que inicia a terceira parte do conto:

Passèrent mille jours, mille nuits, mille roustes.

(Gougaud, 1989, p. 11).

O emprego do quantificador "mil" é a mais pura alusão ao texto fonte: mil e uma noites. A diferença básica entre o texto segundo e o texto base é que as "mil noites" de Sheherazade acontecem em um clima de tranqüilidade. Descobrindo que ao contar histórias ao sultão estaria poupando sua vida $\mathbf{e}$ a das outras mulheres, "mil noites" contou histórias. Porém, a esposa triste "mil noites" de inferno viveu, para só então, descobrindo a vida que crescia em seu ventre, descobrir os contos que trariam a harmonia para a sua casa. 
Finalmente um quarto e último aspecto, entre muitos outros passiveis de ser levantados, é a inversão do momento de contar o conto. Em As mil e uma noites, Sheherazade acordada pela sua irmã Dinarzade, muito antes do amanhecer, começa sua longa narrativa com a intenção de distrair o sultão a ponto de fazê-lo esquecer de sua vingança. Em $A$ mäe dos contos a esposa que todas as noites apanhava do marido, passa a narrar longas histórias que duram toda a noite, de modo que ele não the bata e ela possa poupar a vida de seu filho.

Toute la nuit elle parla. Toute la nuit il l'écouta, (...) Et quand le jour nouveau éclaira la lucarne, elle se tut enfin. Alors il poussa un soupir, vit l'aube, prit sa hache et $s^{\circ} e n$ fut au travail. (Gougaud, 1989, p. 12).

Os contos dAs mil e uma noites transformaram-se em os contos dos nove meses.

Para concluir abordaremos a intertextualidade por fatores tipológicos. É possivel verificar através da estrutura que caracteriza cada tipo de texto ou através de aspectos formais de caráter lingüístico próprios ao texto. Assim, para que um texto seja bem compreendido e visto como coerente, é preciso que apresente certas caracteristicas próprias do tipo de texto do qual ele é apresentado como sendo um exemplar.

Com base em Nádia Battella Gotlib (1990), o que caracteriza o conto é o seu movimento enquanto uma narrativa através dos tempos. Para ela os contos mantêm sempre a mesma estrutura, mudando tão somente, através dos tempos, a técnica de abordagem: o conto permanece, pois, com a mesma estrutura do conto antigo; o que muda é a sua técnica. Segundo ela haveria uma evolução do modo tradicional de contar para o modo moderno de narrar. Segundo o modo tradicional, a ação e o conflito passam pelo desenvolvimento até o desfecho, com crise e resolução tínal. Segundo o modo moderno de narrar, a narrativa desmonta este esquema e se fragmenta numa estrutura invertebrada.

$O$ conto a que nos referimos nesta exposição foi redigido no fim da década de 80 , porém seu autor adota, segundo Gotlib, a técnica tradicional. Há um conflito - a relação violenta do rude lenhador com a esposa triste; há uma crise quando a esposa descobre a sua gravidez e, finalmente, uma resolução final ou um final feliz, quando ela descobre a arte de contar contos. 
Se nos detivermos nos postulados teóricos de Gotlib, veremos que este conto é um exemplo de estrutura do conto antigo com um modo tradicional de narrar. $^{2}$

Cada conto traz um compromisso selado com sua origem: a da história. E com o modo de se contar a história: é uma forma breve. E com o modo pelo qual se constrói este seu jeito de ser, economizando meios narrativos, eles tendem a causar uma unidade de efeito, a flagrar momentos especiais da vida, favorecendo a simetria no uso do repertório dos seus materiais de composição.

A sequiência dos elos que motivam a ocorrência de um conto tende, também, ao desdobramento em mil e uma contingências.

Não há como não nos lembrarmos aqui de Jorge Luis Borges (1971, p. 105-38), que escreve/lê as traduções de Mil e uma noites do capitão Burton, etc., que, por sua vez, leu outras versões árabes, que, por sua vez, foram registradas a partir de outros e milenares contadores...

Se os meses em que a esposa contara os contos se desdobraram em nove, tentando assim permitir o desabrochar de uma vida, parece que as tentativas de se buscar um elemento comum aos contos para além do simples contar histórias, que o liga à sua tradição antiga, tendem também a se desdobrar, tal qual sua antiga tradição, em quase tantas quantas sāo os contos que se contam.

... a palavra não é um objeto, mas um meio constantemente ativo, constantemente mutável de comunicação dialógica. Ela nunca basta a uma consciência, a uma voz. Sua vida está na passagem de boca em boca, de um contexto para o outro, de um grupo social para outro, de uma geração para outra. Nesse processo ela não perde o seu caminho nem pode libertar-se até o fim do poder daqueles contextos concretos que integrou (Bakhtin, 1981, p. 176).

Esta análise demonstrou que os contos dAs mile uma noites permanecem vivos no texto criado por Henri Gougaud. O contexto foi atualizado. As palavras já não são mais as mesmas. Porém, o autor manteve o elo forte que une Sheherazade à esposa triste de um rude lenhador: ambas ousaram, em um ato de coragem, desafiar os seus próprios destinos, preservando suas vidas e de seus semelhantes.

2 Outras aproximaçōes tipológicas seriam possiveis segundo Propp. Bremond e outros estudiosos da narrativa do conto. Porém, tal anílise implicaria em uma desconstrução total do conto, não sendo pois o objetivo desse artigo. 


\section{RESUMO}

Este trabalho apresenta uma leitura intertextual do conto "A mãe dos contos" de Henri Gougaud. Através do estudo do conteúdo, da forma e da tipologia do texto mostramos as similaridades e contrastes entre esse conto e os textos que ai se cruzam.

\section{RESUME}

Ce travail présente une lecture intertextuelle du conte "La mère des contes" d'Henri Gougaud. À travers l'étude du contenu, de la forme et de la typologie du texte on a demontré les similarités et les contrastes entre ce conte et les textes qu'y se croisent.

\section{REFERÊNCIAS BIBLIOGRÁFICAS}

BAKHTIN, Mikhail. Problemas da poética de Dostoiévski. Rio de Janeiro : Forense, 1981. p. 176.

BORGES, Jorge Luis. Los traductores de las 1001 noches. In: Historia de la eternidad (1953). Buenos Aires : Alianza Editorial, 1971. p. 105-30.

GALLAND, Antoine. (trad.) Les milles et une nuits. Paris : Garnier Flammarion 1965. p. 7-51, 442 p.

GOTLIB, Nádia Battella. Teoria do conto. São Paulo : Ática, 1990. 95 p.

GOUGAUD, Henri. La mère des contes. In: . L'arbre d'annour et de sagesse. 1. ed., Paris : Seuil, 1989. p. 11-13.

KOCH, Ingedore G.V. Texto e coerência. São Paulo : Cortez, 1989. 107 p.

KRISTEVA, Julia apud FERREIRA, Edda Arzua. Travessia. Florianópolis : Ed. Universitária, v. 3, 1981, p. 25. 